\title{
Study of anemia in hypothyroid pregnant patients
}

\section{Nidhi Singh, Poonam Mani*, Lalita Yadav, Neha Naresh}

\author{
Department of Obstetrics and Gynecology, Subharti Medical College, Swami Vivekanand Subharti University, \\ Meerut, Uttar Pradesh, India
}

Received: 11 February 2020

Accepted: 04 March 2020

\author{
*Correspondence: \\ Dr. Poonam Mani, \\ E-mail: poonam.mani@rediffmail.com
}

Copyright: (C) the author(s), publisher and licensee Medip Academy. This is an open-access article distributed under the terms of the Creative Commons Attribution Non-Commercial License, which permits unrestricted non-commercial use, distribution, and reproduction in any medium, provided the original work is properly cited.

\section{ABSTRACT}

Background: Hypothyroidism and anemia in pregnancy causes significantly high maternal and fetal morbidity and mortality. Aim of this study was to determine the prevalence of anemia, grade and type of anemia in hypothyroid pregnant patients.

Methods: This prospective study was conducted at department of obstetrics and gynecology, CSSH, Meerut, Uttar Pradesh over a period of 2 years from August 2017 to August 2019. Patients who attended the OPD during the study period were included in the study according the inclusion criteria and were studied for the clinical profile, obstetric history and detailed examination. Investigations were done including hemoglobin, blood grouping, urine routine, HbsAg, Anti-HCV, HIV, RBS and serum TSH. The women with raised serum TSH, indicating hypothyroidism, test for free T3, free T4 and anti-TPO was done, and the hypothyroid females with anemia were further investigated with GBP for the type of anemia, data evaluated with adequate statistical analysis.

Results: A total 223 patients, enrolled in the study, prevalence of anemia in hypothyroid patients was $69.95 \%$. Most patients with overt hypothyroidism had mild anemia $26(68.4 \%)$, while in sub-clinical hypothyroid patients' group most of the patients had moderate anemia. In the overt hypothyroid and subclinical hypothyroid group dimorphic anemia was the most prevalent form of anemia with $52.6 \%$ and $74.6 \%$ respectively.

Conclusions: Prevalence of anemia in hypothyroid pregnant patients is $69.95 \%$. Dimorphic anemia is most prevalent; hence it is important to study anemia in antenatal patients with hypothyroidism and appropriate strategies should be used to prevent and treat anemia.

Keywords: Anemia, Antenatal, Fetal outcomes, Hypothyroid, Maternal outcomes, Pregnancy

\section{INTRODUCTION}

Thyroid Gland diseases affect about $5 \%$ of the general population, and predominantly females. ${ }^{1}$ Thyroid gland dysfunction is relatively common during pregnancy. It has a profound influence on thyroid gland structure as well as function. Hypothyroidism during pregnancy constitutes a significant health challenge, as it is associated with adverse maternal outcome along with an impact on neonatal cognitive development. ${ }^{2,3}$ Anemia is one of the most commonly encountered medical disorders during pregnancy, it is associated with significantly high maternal mortality, and poor fetal outcomes. Thyroid hormones are known to regulate human haematopoiesis in the bone marrow as supported by a large number of studies recently. ${ }^{4-6}$

The association of thyroid disorders and abnormalities in haematological parameters is well known. Hypothyroidism can cause certain forms of anemia on the one hand and hyperproliferation of immature erythroid progenitors on the other hand. The anemia in hypothyroidism is usually macrocytic hypochromic anemia of moderate severity. ${ }^{7}$ In contrast, anemia is not 
frequently observed in patients with hyperthyroidism, whereas erythrocytosis is fairly common. ${ }^{8,9}$ It has been found that all haematological. Treated maternal hypothyroidism is not associated with adverse perinatal outcome. $^{10}$ This study conducted to evaluate the severity and type of anemia in hypothyroid pregnant women.

Objective of this study was to determine the prevalence of anemia, grade of anemia and type of anemia in hypothyroid pregnant patients.

\section{METHODS}

This prospective analytical study was conducted in the department of obstetrics and gynecology, Chhatrapati Shivaji Subharti Hospital, Meerut, Uttar Pradesh over a period of 2 years from August 2017 to August 2019 after prior clearance from the institutional ethics committee. All patients who attended the OPD during the study period were included in the study according to the study protocol.

\section{Inclusion criteria}

- All antenatal females $>18$ years of age who were in the first trimester of pregnancy with hypothyroidism, attending the outpatient department of obstetrics and gynaecology of Chattrapati Shivaji Subharti hospital, Meerut were included in the study.

\section{Exclusion criteria}

- Any patient with pre-pregnancy menstrual irregularities like menorrhagia, or patients with chronic diseases like cardiovascular disease, chronic kidney disease, chronic liver disease, hemorrhoids, or other diseases with gastro intestinal bleeding, tuberculosis, diabetes mellitus, uncontrolled hypertension, haemoglobinopathies, malignancy, patients with bleeding disorders or nutritional deficiencies, patients with multiple pregnancies or obstetric complications like threatened abortion, APH (placenta previa, abruptio placentae) were excluded from the study.

All the antenatal women, fulfilling the criteria were included in the study and written and informed consent were taken. Data was gathered including the clinical profile obstetric history and detailed examination.
Investigations were done including hemoglobin, blood grouping and typing, urine routine examination, $\mathrm{HbsAg}$, anti-HCV, HIV, RBS and serum TSH. The women with raised serum $\mathrm{TSH}$, indicating hypothyroidism, test for free T3, free T4 and anti-TPO was done, and the hypothyroid females with anemia were further investigated with GBP for the type of anemia.

As per the American thyroid association (ATA) guidelines the following cut offs were used as per the below mentioned trimester specific range, first trimester: 0.1-2.5 $\mu \mathrm{IU} / \mathrm{L}$, second trimester: 0.2-3.0 $\mu \mathrm{IU} / \mathrm{L}$, third trimester: $0.3-3.0 \mu \mathrm{IU} / \mathrm{L} .{ }^{11}$ Individuals with haemoglobin level $<11 \mathrm{gm} / \mathrm{dl}$ were classified as anaemic according to the ICMR classification given as follows: anemia $(<11$ $\mathrm{g} / \mathrm{dl})$, mild (>10-10.9 g/dl), moderate $(7-9.9 \mathrm{~g} / \mathrm{dl})$, severe $(4-6.9 \mathrm{~g} / \mathrm{dl})$, very severe $(<4 \mathrm{~g} / \mathrm{dl}){ }^{12}$

\section{Statistical analysis}

All the collected data was entered in Microsoft Excel sheet and then transferred to SPSS software ver. 17 for analysis. Qualitative data was presented as frequency and percentages and analyzed using chi-square test. Quantitative data was presented as mean and SD. p value $<0.05$ was taken as level of significance.

\section{RESULTS}

In the present study, out of all the antenatal patients attending the outpatient during the study period, 223 patients who had hypothyroidism detected during their first antenatal visit were enrolled in the current study. Amongst them the majority of patients i.e. $45.3 \%$ were in 26-30 years age group, followed by the age group of 1925 years which was $37.2 \%$, with a mean age of $27.89 \pm 4.51$ years, as shown in Table 1 .

Table 1: Age group distribution of all antenatal pregnant patients in the study group.

\begin{tabular}{|ll|}
\hline Age & Frequency $\mathbf{n}=\mathbf{2 2 3}(\%)$ \\
\hline$<18$ years & $2(0.9 \%)$ \\
\hline $19-25$ years & $83(37.2 \%)$ \\
\hline $26-30$ years & $101(45.3 \%)$ \\
\hline $31-35$ years & $25(11.2 \%)$ \\
\hline $36-40$ years & $10(4.5 \%)$ \\
\hline$>40$ years & $2(0.9 \%)$ \\
\hline
\end{tabular}

Table 2: Severity of anemia ( $\mathrm{gm} / \mathrm{dl})$ in study population of hypothyroid pregnant patients.

\begin{tabular}{|c|c|c|c|c|}
\hline Grade of anemia (gm/dl) & $\begin{array}{l}\text { Overt hypothyroid } \\
(\mathbf{N}=\mathbf{3 8})\end{array}$ & $\begin{array}{l}\text { Sub-clinical hypothyroid } \\
(\mathrm{N}=118)\end{array}$ & $\begin{array}{l}\text { Total } \\
(N=156)\end{array}$ & $\begin{array}{l}p \\
\text { value }\end{array}$ \\
\hline Mild (10-10.9) & $26(68.4 \%)$ & $52(44.1 \%)$ & $78(50 \%)$ & \multirow{4}{*}{0.005} \\
\hline Moderate (7-9.9) & $11(28.9 \%)$ & $66(55.9 \%)$ & $77(49.4 \%)$ & \\
\hline Severe (4-6.9) & $1(2.6 \%)$ & - & $1(0.6 \%)$ & \\
\hline Very severe & - & - & - & \\
\hline
\end{tabular}


Most of the antenatal patients in the study group were multigravida 125 which is $56.1 \%$ and $43.9 \%$ patients were primigravida, with most of the study population in anaemic patients belongs to upper lower socio-economic class i.e. $35 \%$ followed by lower class i.e. 75 (33.6\%) according to modified Kuppuswamy's socio-economic status scale.

Table 3: Type of anemia (gm/dl) in hypothyroid pregnant patients in the study group.

\begin{tabular}{|c|c|c|c|c|}
\hline Type of anemia & $\begin{array}{l}\text { Overt hypothyroid } \\
(\mathbf{N}=38)\end{array}$ & $\begin{array}{l}\text { Sub-clinical hypothyroid } \\
(\mathrm{N}=118)\end{array}$ & $\begin{array}{l}\text { Total } \\
(\mathrm{N}=156)\end{array}$ & p value \\
\hline Microcytic anemia & $17(44.7 \%)$ & $28(23.8 \%)$ & $42(26.9 \%)$ & \multirow{3}{*}{0.01} \\
\hline Macrocytic anemia & $1(2.6 \%)$ & $2(1.6 \%)$ & $3(1.9 \%)$ & \\
\hline Dimorphic Anemia & $20(52.6 \%)$ & $88(74.6 \%)$ & $101(64.74 \%)$ & \\
\hline
\end{tabular}

Out of 223 antenatal hypothyroid patients included in the study, 156 patients i.e. $69.95 \%$ were anaemic and 67 patients were non-anaemic. As seen Figure 1 prevalence of anemia in hypothyroid patients was $69.95 \%$. Amongst the 223 hypothyroid pregnant patients in the study population, overt hypothyroidism was present in 51 patients amongst whom $24.3 \%$ were anaemic and Sub clinical hypothyroidism was present in 172 patients amongst whom $75.6 \%$ were anaemic.

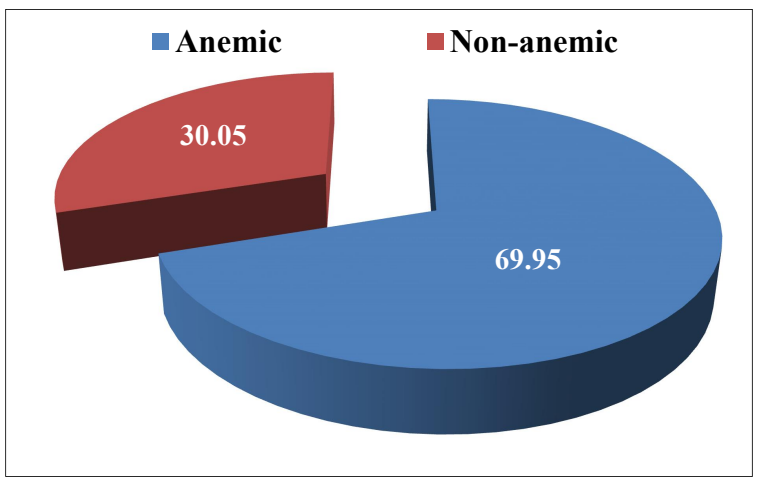

Figure 1: Anaemic and non-anaemic hypothyroid antenatal patients in the study group.

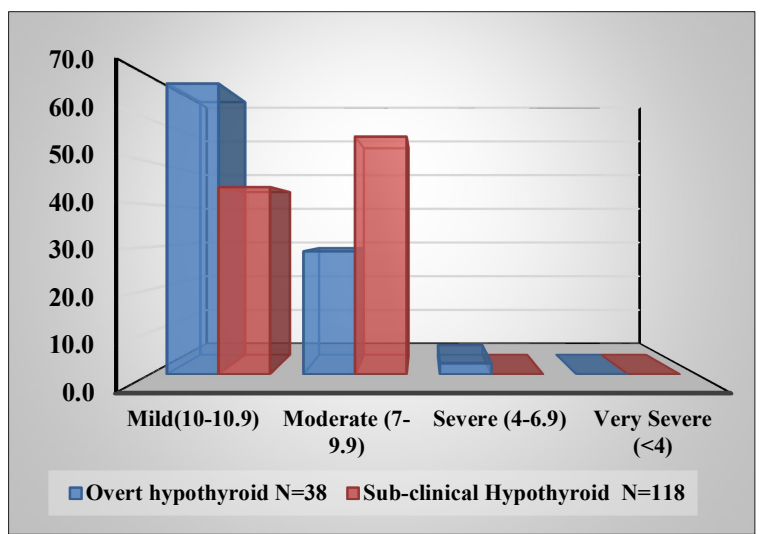

Figure 2: Severity of anemia and type of hypothyroidism.

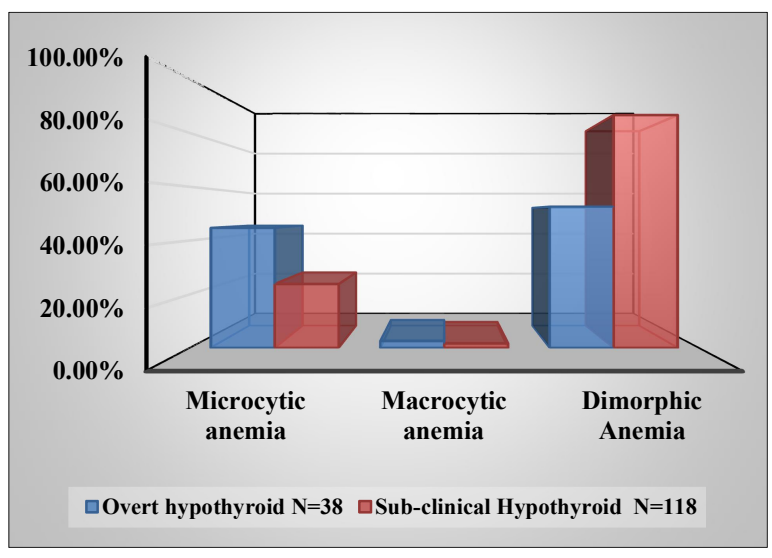

Figure 3: Type of anemia in relation to hypothyroidism.

The grading of the severity of anemia was done using the ICMR classification. As shown in Table 2, most of the patients with overt hypothyroidism had mild anemia 26 $(68.4 \%)$, followed by moderate anemia in 11 patients i.e. $(28.9 \%)$ while in sub-clinical hypothyroid patients group most of the patients had moderate anemia i.e. 66 patients $(55.9 \%)$ followed by mild anemia in 52 patients $(44.1 \%)$ and the difference was statistically significant.

As seen in Table 3, most of the overt hypothyroid patients had dimorphic anemia $20(52.6 \%)$ followed by microcytic anemia $17(44.7 \%)$ and macrocytic anemia 1 $(2.6 \%)$ where as in sub-clinical hypothyroid patients most of the patients had dimorphic anemia 88 (74.6\%) followed by microcytic anemia 28 (23.8\%) and macrocytic anemia $2(1.9 \%)$ and the difference was statistically significant.

\section{DISCUSSION}

In 1881, Charcot showed for the first time that Graves' disease is associated with anaemia. Two years later, Kocher observed a decreased number of red blood cells (RBCs) in the peripheral blood (PB) of patients after thyroidectomy. It has been found that all hematological 
parameters return to normal when an euthyroid state is achieved. ${ }^{13}$ Furthermore, it has been postulated that the influence of THs on hematopoiesis involves an increased production of erythropoietin by non-erythroid cells. ${ }^{14,15}$

In this study, out of all the antenatal patients attending the outpatient department 223 patients who had hypothyroidism were included in first visit in their first trimester and out of them 156 patients had anemia, amongst which the common causes of anemia were ruled out in the exclusion criteria, hence prevalence of anemia in hypothyroid antenatal patients was $69.9 \%$. It has been suggested that nutritional deficiencies are known to develop in hypothyroidism; the most recognized one is iron deficiency. But in this study patient were counselled regarding the causes of anemia, it's prevention and were educated to take adequate balanced diet, according to the diet chart explained to them, to decrease the bias factor in the study. Anemia is estimated to affect up to $60 \%$ of patients with hypothyroidism and is not related to severity or duration of thyroid insufficiency. There is a metabolic deceleration in hypothyroidism. All organ systems are affected. Hematopoietic system is the primary one among these affected systems resulting in anemia. Anemia in hypothyroidism can be normochromic normocytic, microcytic hypochromic, and macrocytic. Hypo cellular structure of the bone marrow gives rise to thought that thyroid hormones play a role in hematopoiesis. The most frequent reason of this is the bone marrow repression due to thyroid hormone deficiency as well as lack of erythropoietin production arising from the reduction in need of $\mathrm{O}_{2} .{ }^{16}$

In this study, most of the study population in anemic patients had subclinical hypothyroid 118 cases $(75.6 \%)$ followed overt hypothyroidism 38 cases $(24.3 \%)$. Most of the patients in overt hypothyroid had mild anemia 26 $(68.4 \%)$ followed by moderate anemia 11 (28.9\%) and severe anemia $1(2.6 \%)$ patients, while in sub-clinical hypothyroid patients most of the patients had moderate anemia $66(55.9 \%)$ followed by mild anemia $52(44.1 \%)$ and the difference was statistically significant, as shown in Figure 2. This result is in accordance with the study conducted by Mamatha $\mathrm{S}$ et al, in which majority of the subjects had anemia with hemoglobin level of $<5 \mathrm{gm}$ as seen in $4(0.4 \%), 17(1.7 \%)$ had haemoglobin of $6-7 \mathrm{gm}$ and $237(23.7 \%)$ had $7.1-10 \mathrm{gm} .^{17}$

In the present study, as shown in Figure 3, most of the patients in overt hypothyroidism had dimorphic anemia $20(52.6 \%)$ followed by microcytic anemia $17(44.7 \%)$ and macrocytic anemia $1(2.6 \%)$ while in sub-clinical hypothyroid patients were most of the patients had dimorphic anemia $88(74.6 \%)$ followed by Microcytic anemia 28 (23.8\%) and Macrocytic anemia 2 (1.7\%) and the difference was statistically significant. This is in accordance with the previous studies by Mehmet et al and Agrawal $U$ et al, who also had the anemia of chronic disease with dimorphic anemia being the commonly present anemia in the peripheral smear. ${ }^{18,19}$ This finding is consistent with the most frequent reason of anemia in hypothyroidism being bone marrow repression due to thyroid hormone deficiency as well as lack of erythropoietin production arising from the reduction in need of oxygen and thyroid hormones also increase 2-3 DPG (diphosphoglycerate) levels assisting in the transmission of oxygen into the tissues. Autoimmune thyroid disorders can be seen with other autoimmune disorders. $^{9,16}$ Pernicious anemia can accompany hypothyroidism as a constituent of auto-immune polyglandular syndrome, hence resulting in dimorphic anemia.

\section{CONCLUSION}

In this study we concluded that the prevalence of anemia in hypothyroid pregnant patients was $69.95 \%$, with such high prevalence in the index study it is worth mentioning that it is important to study anemia in antenatal patients with hypothyroidism and appropriate strategies should be used to prevent and treat anemia in these antennal women. Dimorphic anemia is the most common type of anemia in hypothyroid pregnant patients. Treatment of hypothyroidism with thyroxine is also an essential component for anemia correction and may have a significant effect on anemia related pregnancy outcomes.

Funding: No funding sources Conflict of interest: None declared

Ethical approval: The study was approved by the Institutional Ethics Committee

\section{REFERENCES}

1. Strachan MWJ, Newell-Price J. Endocrine disease. In Davidson Principles and Practice of Medicine, $22^{\text {nd }}$ ed.; Walker BR, Ed.; Churchill Livingstone: Edinburgh, UK; 2014:738-740.

2. De Escobar GM, Obregón MJ, del Rey FE. Maternal thyroid hormones early in pregnancy and fetal brain development. Best Pract Res Clin Endocrinol Metab. 2004; 18:225-48.

3. De Escobar GM, Obregón MJ, del Rey FE. Iodine deficiency and brain development in the first half of pregnancy. Public Health Nutr. 2007;10:1554-70.

4. Tolentino K, Friedman JF. An update on anemia in less developed countries. Am J Med Hyg. 2007;77:44-51.

5. Golde DW, Bersch N, Chopra IJ, Cline MJ. Thyroid hormones stimulate erythropoiesis in vitro. The $\mathrm{Br} \mathrm{J}$ Haematol. 1977;37(2):173-7.

6. Fein HG, Rivlin RS. Anemia in thyroid diseases. Med Clin North Am. 1975;59(5):1133-45.

7. Horton L, Coburn RJ, England JM, Himsworth RL. The haematology of hypothyroidism. Quarterly J Med. 1976;45(177):101-23.

8. Corrocher R, Querena M, Stanzial AM, de Sandre G. Microcytosis in hyperthyroidism: haematological profile in thyroid disorders. Haematol. $1981 ; 66(6): 779-86$. 
9. Perlman JA, Sternthal PM. Effect of 131I on the anemia of hyperthyroidism. J Chronic Dis. 1983;36(5):405-12.

10. Axelrod AR, Berman L. The bone marrow in hyperthyroidism and hypothyroidism. Blood. 1951;6(5):436-53.

11. Matalon S, Sheiner E, Levy A, Mazor M, Wiznitzer A. Relationship of treated maternal hypothyroidism and perinatal outcome. J Reprod Med. 2006;51:59-63.

12. Malgor LA, Blanc CC, Klainer E. Direct effects of thyroid hormones on bone marrow erythroid cells of rats. Blood. 1975;45(5):671-9.

13. Schroeder C, Gibson L, Zenke M, Beug $H$. Modulation of normal erythroid differentiation by the endogenous thyroid hormone and retinoic acid receptors: a possible target for v-erba oncogene action. Oncogene. 1992;7(2):217-27.

14. Leberbauer C, Boulme F, Unfried G, Huber J, Beug $\mathrm{H}$, Mullner EW. Different steroids co-regulate longterm expansion versus terminal differentiation in primary human erythroid progenitors. Blood. 2005;105:85-94.

15. Nekrasova TA, Strongin LG, Ledentsova OV. Hematological disturbanc - es in subclinical hypothyroidism and their dynamics during substitution therapy. Klin Med (Mosk). 2013;91:29-33.

16. Das KC, Mukherjee M, Sarkar TK. Erythropoiesis and erythro - poietin in hypo- and hyperthyroidism. J Clin Endocrinol Metab. 1975;40:211-20.

17. Mamatha S, Mahesh M, Gayathri R, Triveni K. Profile and feto-maternal outcomes of pregnant women with thyroid dysfunction: a prospective study from South India. Int $\mathrm{J}$ Reprod Contracept Obstet Gynecol. 2016;5:4132-5.

18. Mehmet E, Aybike K, Ganıdagli S, Mustafa K. Characteristics of anemia in subclinical and overt hypothyroid patients. Endocrine J. 2012;59(3):213-20.

19. Agrawal U, Shrivastava P, Shrivastava S. Hypothyroidism and anemia in pregnancy. Inter $\mathbf{J}$ Adv Med. 2016;851-4.

Cite this article as: Singh N, Mani P, Yadav L, Naresh N. Study of anemia in hypothyroid pregnant patients. Int J Reprod Contracept Obstet Gynecol 2020;9:1686-90. 